\title{
Sensory, Functional, and Analytical Comparisons of Whey Butter with Other Butters ${ }^{1}$
}

\author{
S. Jinjarak, ${ }^{*}$ A. Olabi, ${ }^{* 2,3}$ R. Jiménez-Flores, $\dagger$ and J. H. Walkerł \\ ${ }^{*}$ Food Science and Nutrition Department, \\ †Dairy Products Technology Center, and \\ ‡Statistics Department, California Polytechnic University, San Luis Obispo 93407
}

\section{ABSTRACT}

The objective of this work was to characterize the sensory attributes of whey (WB), cultured (CB), and regular sweet cream (SB) unsalted butters produced at the Dairy Products Technology Center (experimental; $\mathrm{n}=3$ ) or obtained from commercial sources ( $\mathrm{n}=$ 6). Nine judges were trained for nine 1-h sessions; they then rated samples on a $15-\mathrm{cm}$ line scale in triplicate using descriptive analysis. Data obtained were analyzed using SAS statistical software. Significant differences between the 3 types of butters were obtained on yellow, shiny, acidic odor, melt rate, porous, hard, spreadable, cheese odor, mouthcoating, nutty, cardboard odors, acidic, nutty, diacetyl, and grassy flavors. Cultured butter and SB were significantly shinier than WB. Whey butter was more yellow than CB, which in turn was more yellow than SB. Whey butter was more porous, and had higher scores on nutty flavor and cardboard odor than SB and CB. Sweet cream butter was significantly harder than CB but not WB. Cultured butter had more mouthcoating, acidic odor and flavor, and grassy flavor than SB and WB. The commercial samples were more porous, crumbly, and had significantly more artificial butter odor, rancid odor, and flavor. Results from principal component analysis indicated that experimental WB and SB were similar and were characterized by a sweet taste. Whey butter's characteristics compared favorably with commercial $\mathrm{CB}$ and were very similar to sweet cream butter. No major significant differences were obtained for triangle tests, with the exception of that for WB and CB in pound cake. No significant differences were obtained

\footnotetext{
Received August 31, 2005.

Accepted November 17, 2005.

${ }^{1}$ Use of names, names of ingredients, and identification of specific models of equipment is for scientific clarity and does not constitute any endorsement of product by authors, California Polytechnic State University (San Luis Obispo), the Dairy Products Technology Center, or the American University of Beirut.

${ }^{2}$ Corresponding author: ammar.olabi@aub.edu.lb

${ }^{3}$ Current address: Nutrition and Food Science Department, Faculty of Agricultural and Food Sciences, American University of Beirut, Riad El Solh, 1107 2020, Beirut, Lebanon.
}

for the acceptability of the different versions of any of the 3 foods.

Key words: butter, buttermilk, sensory evaluation, whey

\section{INTRODUCTION}

For the past $20 \mathrm{yr}$, consumers have been reducing their fat consumption due to health concerns surrounding animal saturated fats and high-fat diets. This trend has affected several dairy ingredients including butter. Butter production has decreased from 596.6 to 563.5 million $\mathrm{kg}$ in the last $10 \mathrm{yr}$ (Dairy Facts, 2004) due to several reasons, mainly nutritional and economical. Because of obesity and dietary-related diseases, there is an opportunity for researchers to modify the formulation of staple dairy foods (such as butter) ideally without any major loss of the inherent sensory properties.

Butter is mostly made by continuous churn in the United States. Different types of butter are available on the market such as sweet cream (salted or unsalted), cultured, and whipped butter. Cultured cream butter, as the name suggests, is cultured with lactic bacteria and is usually characterized by its intense diacetyl flavor (Bodyfelt et al., 1988). Sweet cream butter, on the other hand, has a higher $\mathrm{pH}$ and accordingly a shorter shelf life. Whipped butter has better spreadability due to its inclusion of whipped nitrogen gas (Bodyfelt et al., 1988). Whey butter, which is produced using whey cream, has been gaining attention from the dairy industry due to the large volumes of whey and whey cream produced by the cheese manufacturing industry (Srivastava et al., 1985). Whey cream is removed from whey after cheese making and before whey is processed for spray drying or protein concentration. There is currently no practical use for this coproduct, and it is being absorbed at almost no value by the butter industry. Any research contributing to better valorization of this product would be valuable to butter manufacturers.

Total whey products produced in the United States comprised 852.5 million $\mathrm{kg}$ in 1993; production in- 
creased to 985.2 million $\mathrm{kg}$ in 2003 . The need to process whey has increased because of its economical importance at the industry level. Cost of storage- and sewage-associated expenses for whey have decreased because of an increase in reprocessing whey, for example, into animal feed (Maubois et al., 1987) or recovering whey proteins as whey protein concentrate.

Whey cream is higher than sweet cream in unsaturated fat and biologically active compounds that originate from the milk fat globule membrane, such as sphingomyelin and mucins (R. Jiménez-Flores, personal communication). Studies suggest that sphingomyelin may help prevent the onset of cancer and control the growth of cancerous cells (Parodi, 1999). Experimental results showed that sphingomyelin was more retained in the fat globule membrane than other phospholipids (Bitman and Wood, 1990).

The sensory analysis of butter has not been a subject of exhaustive study. Historically, butter was sensorially assessed and graded by USDA dairy judges. The grading is based on flavor, body, color, and salt content (USDA, 1977) with a focus on 8 defects; the temperature of butter is usually set between 7 and $13^{\circ} \mathrm{C}$ for grading.

Several studies included assessment of the odor compounds in butter. The compounds that were identified for different types of butters included $\delta$-decanolactone and butanoic acid (Schieberle et al., 1993); 2-methylbutanal, dimethyl trisulfide, and 2,3-butanedione (Peterson and Reineccius, 2003a); dimethyl sulfide and skatole (Schieberle et al., 1993); and lactones and carbonyl compounds (Peterson and Reineccius, 2003b).

Several studies have involved sensory evaluation of butter, with a focus on texture (Mortensen and Danmark, 1982; Kulkarni and Rama-Murthy, 1986; Rohm and Ulberth, 1990; Kaylegian and Lindsay, 1992; Kleyn, 1992; Stegeman et al., 1992; Wright et al., 2001). In addition, sensory panels have been used to show that butter made from unsaturated fatty acid diet treatments with bST had acceptable flavor and did not have a detectable rancid off-flavor after 3 mo of cold storage (Stegeman et al., 1992). Bobe et al. (2003) examined the effect of phenotype on the milk fat composition of dairy cows fed identical diets and the texture of the butters made from their milk. Their sensory panel found that the dairy cows whose milk had a low atherogenic index, an indicator for cardiovascular disease, for lipids produced butters that were softer, less adhesive, and more spreadable at $5^{\circ} \mathrm{C}$ than butter samples from the high-atherogenic index group. Similar findings were obtained by Lin et al. (1996) who supplemented the bovine diet with calcium salts of sunflower oil, with high oleic acid content, and obtained a softer and more spreadable butter, especially for the high oleic acid butter. Several studies (Lin et al., 1996; Bobe et al., 2003; Chen et al., 2004) revealed that, although texture changes with the milk fatty acid composition, the effect on flavor is not significant. None of these studies has included extensive descriptive analysis of different butters and a comprehensive characterization of their attributes.

Creating new applications for the different whey components, such as whey butter, in food products is very promising for the dairy industry. It could be beneficial for consumers because of the potential benefit of added nutritional compounds, such as the minor components in milk fat globule membrane, but could also be economical by giving more value to these ingredients. Despite the decrease in butter consumption and its relatively standard flavor and texture profile, there remains a need for a comprehensive sensory characterization of butter. Therefore, the objectives of this work were first, to assess the physicochemical properties and sensory characteristics of sweet cream, whey and cultured butters, and second, to assess the potential of the various types of butters in food applications.

\section{MATERIALS AND METHODS}

\section{Treatments}

Formulations. Samples consisted of 6 unsalted commercial butters ( 3 sweet cream, 1 whey, and 2 cultured butters) and 3 unsalted experimental samples, one of each category [cultured butter (CB), sweet cream butter (SB), and whey butter (WB)]. Commercial samples were provided by dairy companies in California in sufficient quantity from 2 production dates.

Processing. Two trials of butter making were performed at the Dairy Products Technology Center at California Polytechnic State University (San Luis Obispo) for each type of butter (SB, CB, and WB). Experimental butters were processed using the same procedures as described by Sodini et al. (2006). Sweet cream and whey cream were provided by Foster Farms (Modesto, CA) and Hilmar Cheese Company (Hilmar, CA), respectively; for each trial, 100 to $200 \mathrm{~L}$ of cream was churned after a waiting period of $16 \mathrm{~h}$ at $4^{\circ} \mathrm{C}$. Sour cream was produced at DPTC from sweet cream (Foster Farms). The cream was preheated at $20^{\circ} \mathrm{C}$, inoculated with $0.07 \%$ (wt/wt) commercial mesophilic culture Flora Danica (Lactococcus lactis, Lactococcus cremoris, Leuconostoc cremoris, and L. lactis diacetylactis; Chr. Hansen, Milwaukee, WI), incubated at the same temperature for $16 \mathrm{~h}$, and finally churned. The final $\mathrm{pH}$ of sour cream was $4.90 \pm 0.05$. The 3 creams (sweet, sour, and whey cream) were churned 
to butter using a continuous pilot scale butter churn (Egli AG, Bütschwil, Switzerland).

Storage. All the experimental (made at Dairy Products Technology Center) butters (CB, SB, and WB) were vacuum-sealed in 3-mil polyethylene bags, placed in cardboard boxes, and stored at $-34^{\circ} \mathrm{C}$. The commercial samples were stored at the same temperature. The samples were then tempered at $5^{\circ} \mathrm{C}$ for $3 \mathrm{~d}$, and stored at a $10^{\circ} \mathrm{C}$ refrigerator for 6 to $8 \mathrm{~h}$ before sensory evaluation.

\section{Physical and Chemical Analyses}

Composition. Fat content was determined using 1 $\mathrm{g}$ of butter sample by the Mojonnier method (AOAC, 1996; method no. 33.2.26; 989.05). Protein content was determined by the bicinchoninic acid (BCA) assay method (BCA protein assay kit, Pierce, Rockford, IL). Samples were placed in 50-mL Falcon tubes and heated in an $80^{\circ} \mathrm{C}$ water bath for approximately 20 min or until completely melted. Melted samples were then separated into fat and aqueous phases by centrifuging (model 5810R, Eppendorf, Hamburg, Germany) 3 times at $2,683 \times g$ for $15 \mathrm{~min}$ at $40^{\circ} \mathrm{C}$. The fat layer on top was removed each time after centrifuging and the aqueous phase was retained for the BCA assay. Protein analysis was determined using the BCA assay according to the manufacturer's instructions. Total solids content was determined using the AOAC method (AOAC, 1996; method no. 33.3.07; 920.107) and ash content was determined by placing dried samples in a Muffler Isotemp programmable forced draft furnace (Fisher Scientific, Tustin, CA) at $550^{\circ} \mathrm{C}$ (AOAC 1996; method no. 33.6.05; 920.117). Lactose was calculated by difference on a DM basis as 100 - (protein + fat + ash). All chemical analyses were done in duplicate. Results were reported using the means of duplicates.

Hardness. Hardness of the samples was analyzed using a texture analyzer (TATX2 Texture Analyzer, Texture Technologies Corp., Scarsdale, NY), and measured by the maximum force in grams required to penetrate through a $2.54-\mathrm{cm}$ sample using a $60^{\circ}$ cone. The cone penetration was set at $10 \mathrm{~mm}$ depth and at a speed of $2.0 \mathrm{~mm} / \mathrm{s}$. Butter samples were removed from the $-34^{\circ} \mathrm{C}$ freezer, stored in a $5^{\circ} \mathrm{C}$ refrigerator for approximately $12 \mathrm{~h}$ to soften, cut into $1-\mathrm{cm}$ cubes, and placed in a $10^{\circ} \mathrm{C}$ refrigerator until measurement.

Color. Color was determined using the Hunter LAB Colorimeter, UltraScan XE (Hunter Associates Laboratory, Reston, VA). Butter samples were prepared by spreading the sample in the Petri dish to a thickness of approximately $1.27 \mathrm{~cm}$.

Melting Point. Differential scanning calorimetry (DSC; Refrigerated Coding System TA Instruments,
Thermal Analysis + Rheology, New Castle, DE) was used to measure the melting point of butter samples using $10 \mathrm{mg}$ of butter fat. Initial temperature of samples was set at $65^{\circ} \mathrm{C}$, held at the isothermal point $\left(65^{\circ} \mathrm{C}\right)$ for $5 \mathrm{~min}$, decreased at $10^{\circ} \mathrm{C} / \mathrm{min}$ to $-40^{\circ} \mathrm{C}$, held again at isothermal point for another $5 \mathrm{~min}$, and increased at $5^{\circ} \mathrm{C} / \mathrm{min}$ to $65^{\circ} \mathrm{C}$. Temperatures recorded were compared between the 3 types of butters and between production sites based on the 3 maximum peaks, the highest peak being the high-melting point of glycerides in butter where all triglycerides were melted; the other 2 peaks represented the low-melting and middle-melting glycerides (Cebula and Smith, 1991), where some of triglycerides were melted but not all. Differential scanning calorimetry, in particular, measures the absorbing heat when heating and cooling as compared with the reference, an empty pan (Kaylegian and Lindsay, 1994).

\section{Descriptive Analysis}

Nine panelists ( 7 females, 2 males, ages 21 to 37 ), who were students, staff, and faculty at California Polytechnic State University were trained over nine 1-h sessions, 3 times a week, for 3 wk. The training included evaluation of both commercial and experimental samples. The training included tasting different butter samples and discussing their characteristics. The panelists generated 25 sensory attributes and definitions in the training sessions, along with reference standards for several of the attributes (Table 1).

During the evaluation period, the panelists attended 18 sessions (1 morning and 1 afternoon session each day) for a 3-d period per week over $3 \mathrm{wk}$. Three samples were served at each session. The order of the samples was randomized for the panelists over the 3-d period for each week. There were 3 replicate evaluations (1/ wk) with all 18 samples ( 9 samples $\times 2$ batches $)$ served within each week. Samples were cut into $2.54-\mathrm{cm}^{2}$ cubes and placed in a $10^{\circ} \mathrm{C}$ refrigerator for 2 to $3 \mathrm{~h}$ before serving. Butter samples $\left(10^{\circ} \mathrm{C}\right)$ were served monadically in individual booths, in 148 - $\mathrm{mL}$ foam cups labeled with 3-digit numbers. References were given to panelists. Panelists were instructed to rinse their mouths with spring water and cleanse their palates with unsalted crackers (Carrs Water Crackers, Cheese Express, Santa Cruz, CA) before each sample and to expectorate all water and butter. Attributes were rated on a $15-\mathrm{cm}$ line scale. Judges were compensated with gift certificates to local stores of their choice.

\section{Difference Tests and Hedonic Evaluation}

Each type of butter (CB, WB, and SB) was formulated with other ingredients to make 3 different foods: 
Table 1. Terms used in descriptive analysis of sweet cream, whey and cultured butters

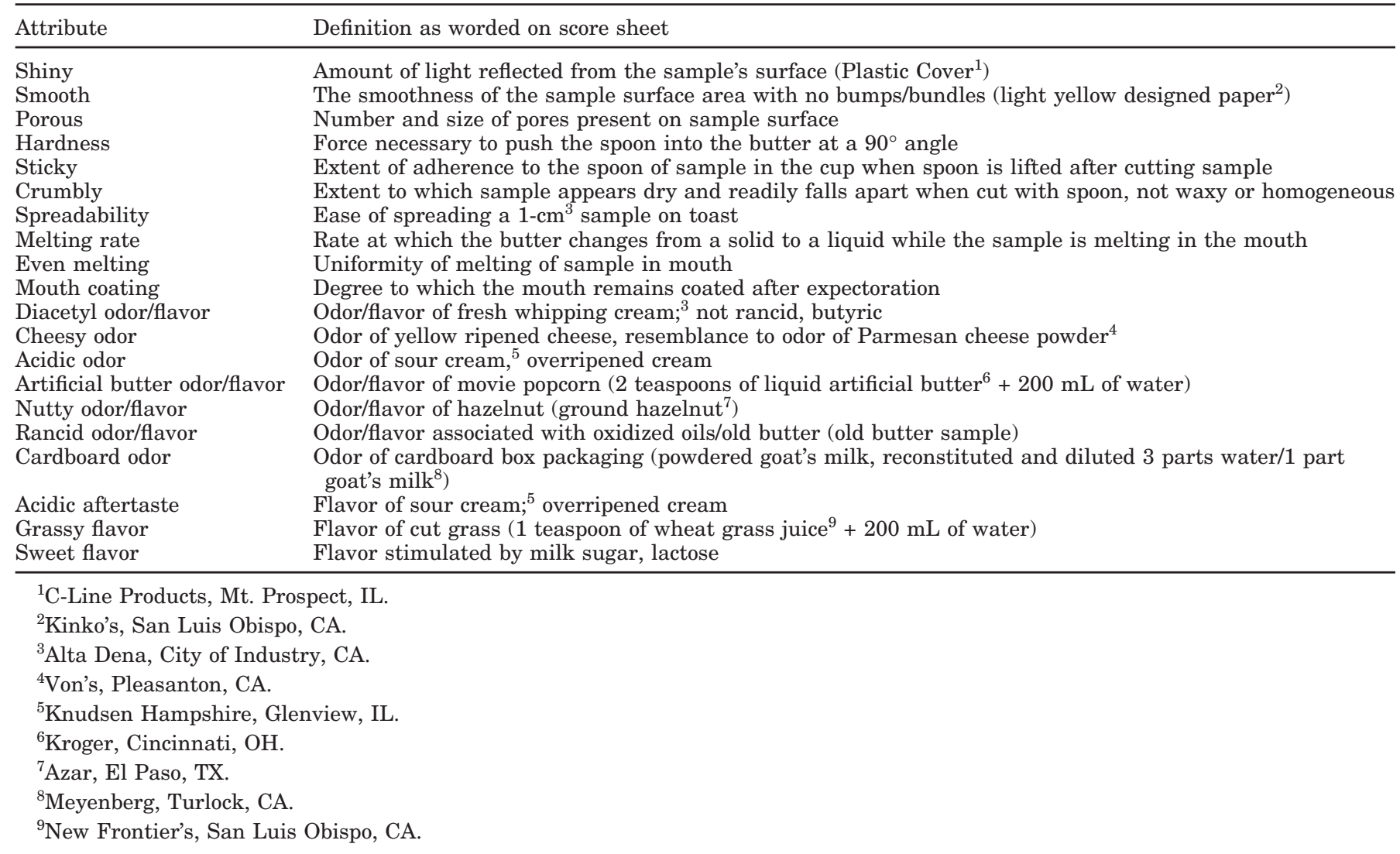

pie crust, pound cake, and shortbread, yielding 9 samples, with 3 versions of each product. The 3 food products were selected based on preliminary trials and on the fact that butter was a main ingredient in them, playing a major role in terms of functionality and sensory properties. Three days of evaluation were dedicated for difference and acceptability tests; $1 \mathrm{~d}$ for each food product. Three triangle tests were given to 40 untrained volunteers, 1 set of 3 samples at a time. Each triangle test included 2 versions of the same product (e.g., CB vs. WB shortbread). The 3 different pairs of samples were tested for each food product. The order of the samples within each set as well as the order of the different sets was randomized among the panelists. Panelists were asked to indicate the odd sample in each set. Panelists were instructed to rinse their mouths before each sample.

Consumer acceptance was determined by asking 40 untrained volunteers from the university to indicate their degree of liking on a 9 -point scale $(1=$ dislike extremely to 9 = like extremely). Panelists were instructed to rinse their mouths before each sample. Serving order was randomized. All products were served in 59-mL plastic containers (Dixie Clear Plastic
Souffle Cup Lid, Georgia Pacific Dixie, Atlanta, GA) in individual booths. Panelists were rewarded with a gift certificate to an on-campus cafeteria.

\section{Statistical Analyses}

Data related to triangle tests were analyzed by checking the minimum number of correct responses using a binomial table with $\alpha=0.05$ (Lawless and Heymann, 1999). Data related to physical, chemical, and sensory analyses were analyzed using the Proc Mixed procedure of SAS (version 8.02, 1999-2001, SAS Institute Inc., Cary, NC). An ANOVA was performed to evaluate the effects of type (CB, SB, and WB), site of production (commercial vs. experimental), replicate, and their interactions. Significant means for the physical and chemical analyses and the sensory analyses were separated by Tukey's honestly significant difference (HSD) test. Significance was preestablished at $\alpha$ $<0.05$. The lack of balance for the samples between types of butter (total of $4 \mathrm{SB}, 2 \mathrm{WB}$, and $3 \mathrm{CB}$ ) was taken into account and adjustment was made for these differences statistically by including a factor in our model for the butter. This factor was butter nested 
Table 2. Significance of the effects of type (sweet cream, whey, and cultured), site of production (commercial vs. experimental), replicate, and interactions on the physical and chemical properties of butter samples

\begin{tabular}{lccllll}
\hline & \multicolumn{5}{c}{ Effects } \\
\cline { 2 - 6 } $\begin{array}{l}\text { Chemical } \\
\text { analyses }\end{array}$ & $\begin{array}{l}\text { Type } \\
\mathrm{df}=2\end{array}$ & $\begin{array}{l}\text { Site } \\
\mathrm{df}=1\end{array}$ & $\begin{array}{l}\text { Replicate } \\
\mathrm{df}=2\end{array}$ & $\begin{array}{l}\text { Site } \times \text { Type } \\
\mathrm{df}=4\end{array}$ & $\begin{array}{l}\text { Type } \times \text { Rep } \\
\mathrm{df}=2\end{array}$ & $\begin{array}{l}\text { Site } \times \text { Rep } \\
\mathrm{df}=1\end{array}$ \\
\hline Fat & 2.62 & 2.51 & 0.32 & $5.45^{*}$ & 0.01 & 0.02 \\
Protein & 0.58 & 0.23 & 2.66 & 0.01 & 0.01 & 0.13 \\
Solid & 2.61 & $19.56^{* *}$ & 0.12 & 0.57 & 0.49 & 1.81 \\
Ash & 1.52 & 2.78 & 0.71 & 0.86 & 1.62 & 0.31 \\
Lactose & 2.66 & 2.65 & 0.40 & $5.69^{*}$ & 0.00 & 0.03 \\
pH & 12.12 & 0.96 & 0.26 & 0.28 & 0.05 & 2.51 \\
Texture & $10.71^{*}$ & 0.55 & 0.05 & 3.04 & 0.46 & 0.47 \\
Color L & 0.80 & 1.65 & 1.11 & 0.17 & 2.53 & 1.01 \\
Color a & 0.47 & 2.68 & 0.24 & 1.19 & 0.14 & 0.01 \\
Color b & 1.40 & 0.10 & 4.57 & 1.25 & 0.85 & 2.88 \\
\hline
\end{tabular}

$* P<0.05 ; * * P<0.01$.

within type and location [butter (type $\times$ location)]. Two batches of each butter sample and type were produced and given to the 9 subjects so that the design for each of the 9 butters was balanced. Any potential problems caused by an uneven number of commercial butters within each type were removed by including this butter term in the model.

It is important to note that, from a statistical standpoint, the results include tests of 10 different physical and chemical properties and 25 different sensory attributes for 6 different main effects and interactions. With a 5\% significance level attached to each test, the chance of incorrectly finding a significant difference in at least one of these tests is extremely high. Accordingly, it is safest to assume that only the tests with a $P$-value $<0.001$ show a real difference and that tests with $P$-values between 0.001 and 0.05 should be interpreted with caution. In addition, principal components analysis was performed using the 27 means from the 9 different butter samples for each of the 3 replications using SAS.

\section{RESULTS AND DISCUSSION}

\section{Physical and Chemical Analyses}

Results of the chemical and physical analyses, with the exception of DSC analysis, are summarized in Tables 2 and 3. A significant type effect was obtained for texture (Table 2). Whey butter had the softest texture, whereas SB was the hardest (Table 3). Cultured butter was not significantly different from the other 2 types. There were no significant differences between the different types of butters on the other physical and chemical measurements, except for $\mathrm{pH}$, which was lowest for CB (Table 3). A significant site effect was noted for total solids content $(P<0.01)$. The experimental butters had higher (approximately $4 \%$ more) total sol- ids than the commercial butters. In addition, significant site $\times$ type interactions were found for fat and lactose content $(P<0.05)$. A more careful look at the means of for the 6 combinations of site and type revealed that experimental SB was much higher in lactose and lower in fat than the other butters, which was not the case for commercial SB. Because of the conservative nature of Tukey's HSD comparisons, the means were not significantly different even though their tests in Table 2 showed a significant interaction effect. The processing technique could have also influenced the composition of butter as evident by the significant difference in total solids between the 2 production sites. No significant differences were obtained between the replicates or for the type $\times$ replicate and site $\times$ replicate interactions.

The results for DSC measurements are illustrated in Figure 1. Average melting points of commercial and experimental butters were $33.82,34.24$, and $32.88^{\circ} \mathrm{C}$ for $\mathrm{SB}, \mathrm{WB}$, and $\mathrm{CB}$, respectively. Higher unsaturated fat such as oleic acid in butter improved texture making it softer and more spreadable than regular butter even at refrigerator temperature (Lin et al., 1996). Guthrie (1928) stated that SB had an average melting point of $36.17^{\circ} \mathrm{C}$, whereas WB had an average of $35.70^{\circ} \mathrm{C}$. Curves for the same type of butter were similar for the experimental and commercial samples. Accordingly, it seems that type of butter dictates the DSC profile more than source or site of production.

\section{Descriptive Analysis}

ANOVA and HSD. The results of the ANOVA for sensory data, including the $F$-values and probability levels for the different attributes, are summarized in Table 4. Least squares means are summarized in Tables 5 and 6 . The ANOVA revealed significant differ- 
Table 3. Least squares means of the physical and compositional properties of butter samples (dry basis) for the 3 butter types (sweet cream, whey, and cultured) and the 2 production sites (commercial and experimental)

\begin{tabular}{|c|c|c|c|c|c|}
\hline & \multicolumn{3}{|c|}{ Type } & \multicolumn{2}{|c|}{ Production site } \\
\hline & Whey & Sweet cream & Cultured & Experimental & Commercial \\
\hline \multicolumn{6}{|c|}{ Chemical analyses } \\
\hline Fat & 95.80 & 96.03 & 93.03 & 94.11 & 95.80 \\
\hline Protein & 0.75 & 0.92 & 0.89 & 0.88 & 0.82 \\
\hline Solid & 87.66 & 86.02 & 88.20 & $89.16^{\mathrm{a}}$ & $85.42^{\mathrm{b}}$ \\
\hline Ash & 0.09 & 0.12 & 0.15 & 0.10 & 0.15 \\
\hline Lactose & 3.36 & 2.93 & 5.93 & 4.91 & 3.24 \\
\hline \multicolumn{6}{|c|}{ Physical analyses } \\
\hline $\mathrm{pH}$ & $6.36^{\mathrm{a}}$ & $6.12^{\mathrm{a}}$ & $4.87^{\mathrm{b}}$ & 5.64 & 5.92 \\
\hline Texture $^{1}$ & $1,792.5^{\mathrm{b}}$ & $2,752.9^{\mathrm{a}}$ & $2,232.4^{\mathrm{ab}}$ & $2,196.9$ & $2,321.60$ \\
\hline Color L & 82.62 & 85.89 & 85.14 & 86.01 & 83.09 \\
\hline Color a & -1.71 & -1.37 & -1.45 & -1.22 & -1.80 \\
\hline Color b & 20.04 & 20.96 & 22.46 & 20.94 & 21.37 \\
\hline
\end{tabular}

${ }^{\mathrm{a}, \mathrm{b}}$ Means with different letters are significantly different $(P<0.05)$.

${ }^{1}$ Texture $=$ Maximum force in grams required to penetrate through samples.

ences between the types of butter on yellowness, shininess, melting rate, and acidic odor $(P<0.001)$; porousness, hardness, spreadability, and cheesy odor, $(P<$ 0.01); mouthcoating, nutty odor, cardboard odor, acidic flavor, nutty flavor, diacetyl flavor, and grassy flavor $(P<0.05)$. These differences between butter types are modified by the presence of significant butter type $x$ production site interactions associated with yellowness, porousness, crumbliness, hardness, spreadability, melting rate, even melting, and cheesy odor, artificial butter odor, and nutty odor $(P<0.001)$; smoothness, diacetyl odor, rancid odor, nutty flavor $(P$ $<0.01$ ); and shininess, acidic odor, cardboard odor, and artificial butter flavor $(P<0.05)$. In these cases, the

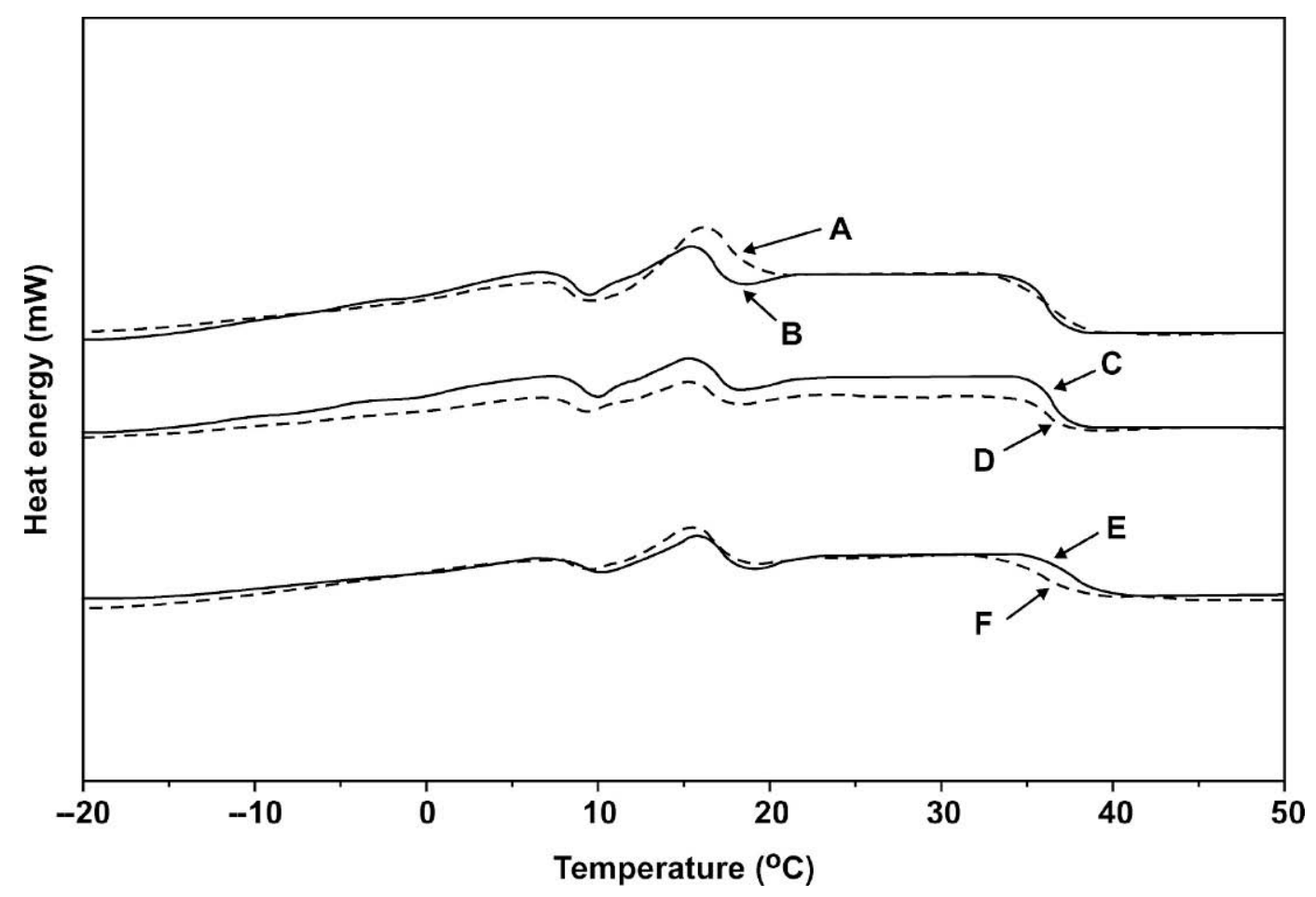

Figure 1. Differential scanning calorimetry for types of butters (cultured, whey, and sweet cream) from 2 sites (experimental and commercial). $\mathrm{A}=$ Commercial cultured butter; $\mathrm{B}=$ experimental cultured butter; $\mathrm{C}=$ experimental sweet cream butter; $\mathrm{D}=\mathrm{commercial}$ sweet cream butter; $\mathrm{E}=$ experimental whey butter; and $\mathrm{F}=$ commercial whey butter. 
Table 4. Significance of effects of type (sweet cream, whey, and cultured), site of production (experimental and commercial), replicate, and interactions on the sensory properties of butter samples

\begin{tabular}{|c|c|c|c|c|c|c|}
\hline \multirow[b]{2}{*}{ Attributes } & \multicolumn{6}{|c|}{ Effect } \\
\hline & $\begin{array}{l}\text { Type } \\
\mathrm{df}=2\end{array}$ & $\begin{array}{l}\text { Site } \\
\mathrm{df}=1\end{array}$ & $\begin{array}{l}\text { Replicate } \\
\mathrm{df}=2\end{array}$ & $\begin{array}{l}\text { Type } \times \text { Site } \\
\mathrm{df}=2\end{array}$ & $\begin{array}{l}\text { Type } \times \text { Rep } \\
\mathrm{df}=4\end{array}$ & $\begin{array}{l}\text { Site } \times \text { Rep } \\
\mathrm{df}=2\end{array}$ \\
\hline Shiny & $7.64^{* * * *}$ & 1.03 & 0.48 & $3.49 *$ & 0.11 & $3.30 *$ \\
\hline Yellow & $34.70 * * *$ & $17.04 * * *$ & 2.47 & $32.77 * * *$ & 1.70 & 0.12 \\
\hline Smooth & 2.65 & 2.61 & 2.28 & $8.43 * *$ & 1.14 & 1.69 \\
\hline Porous & $10.52^{* *}$ & $11.17 * *$ & 0.54 & $21.10 * * *$ & 0.28 & 1.13 \\
\hline Hard & $6.56^{* *}$ & 2.48 & $8.13 * *$ & $9.24^{* * * *}$ & 1.59 & 0.77 \\
\hline Sticky & 1.62 & 1.63 & $7.13^{* * *}$ & 0.54 & 0.86 & 0.29 \\
\hline Crumbly & 0.40 & $25.37 * * *$ & 1.20 & $15.65^{* * *}$ & 1.24 & 0.04 \\
\hline Spreadable & $11.34^{* *}$ & $33.05^{* * *}$ & 1.44 & $13.03 * * *$ & 1.60 & 0.78 \\
\hline Melt rate & $11.61^{* * *}$ & $9.61^{*}$ & 0.60 & $7.08^{* * * *}$ & 1.70 & 0.16 \\
\hline Even melt & 1.94 & $17.22 * *$ & 0.19 & $14.12^{* * *}$ & $2.58^{*}$ & 1.44 \\
\hline Mouthcoating & $3.93^{*}$ & 0.23 & 0.66 & 0.35 & 0.19 & 0.57 \\
\hline Diacetyl odor & 1.10 & 0.33 & 0.48 & $5.27 * *$ & 0.85 & 0.05 \\
\hline Cheesy odor & $8.07 * *$ & 3.36 & $4.44^{*}$ & $13.16^{* * *}$ & 0.62 & 0.10 \\
\hline Acidic odor & $12.79 * * *$ & 4.12 & 0.84 & $4.20^{*}$ & 0.48 & 0.14 \\
\hline Artificial butter odor & 2.46 & 4.24 & 3.29 & $8.46^{* * * *}$ & 0.50 & 0.29 \\
\hline Nutty odor & $3.90^{*}$ & 0.67 & $3.72 *$ & $7.62^{* * * *}$ & 1.02 & 0.45 \\
\hline Rancid odor & 1.98 & $10.64^{* *}$ & 1.33 & $6.01^{* *}$ & 1.45 & 1.45 \\
\hline Cardboard odor & $6.11^{*}$ & 2.59 & 1.37 & $5.39 *$ & 0.68 & 0.61 \\
\hline Acidic flavor & $4.85^{*}$ & $4.87^{*}$ & 2.27 & 1.95 & 0.34 & 0.48 \\
\hline Nutty flavor & $5.28^{*}$ & 0.52 & 1.62 & $5.47^{* *}$ & 0.87 & 0.22 \\
\hline Rancid flavor & 3.01 & $6.95^{*}$ & 0.19 & 2.00 & 1.32 & $3.62 *$ \\
\hline Artificial butter flavor & 1.06 & 1.03 & 2.43 & $5.55^{*}$ & 0.30 & 0.83 \\
\hline Diacetyl flavor & $3.70^{*}$ & $5.68 *$ & 0.93 & 2.19 & 0.49 & 0.98 \\
\hline Grassy flavor & $5.40 *$ & 1.31 & $4.43 *$ & 0.41 & 1.07 & 1.22 \\
\hline Sweet flavor & 3.01 & 0.51 & 1.59 & 0.36 & 0.40 & 2.95 \\
\hline
\end{tabular}

$* P<0.05, * * P<0.01, * * * P<0.001$

Table 5. Least squares means of descriptive analysis attributes for butter type (sweet cream, whey, and cultured) and site of production (experimental and commercial) butter samples

\begin{tabular}{|c|c|c|c|c|c|}
\hline \multirow[b]{2}{*}{ Attributes } & \multicolumn{3}{|c|}{ Type } & \multicolumn{2}{|c|}{ Production site } \\
\hline & Whey & Sweet cream & Cultured & Commercial & Experimental \\
\hline Shiny & $6.54^{\mathrm{b}}$ & $7.62^{\mathrm{a}}$ & $8.31^{\mathrm{a}}$ & 7.35 & 7.63 \\
\hline Yellow & $9.04^{\mathrm{a}}$ & $6.36^{\mathrm{b}}$ & $8.08^{\mathrm{a}}$ & $7.23^{\mathrm{b}}$ & $8.43^{\mathrm{a}}$ \\
\hline Smooth & 9.39 & 10.64 & 10.44 & 9.67 & 10.64 \\
\hline Porous & $4.43^{\mathrm{a}}$ & $2.41^{\mathrm{b}}$ & $2.38^{\mathrm{b}}$ & $3.83^{\mathrm{a}}$ & $2.31^{\mathrm{b}}$ \\
\hline Hard & $6.82^{\mathrm{ab}}$ & $7.48^{\mathrm{a}}$ & $5.63^{\mathrm{b}}$ & 6.82 & 6.47 \\
\hline Sticky & 6.68 & 6.37 & 7.34 & 6.35 & 7.25 \\
\hline Crumbly & 5.93 & 5.21 & 5.23 & $7.67^{\mathrm{a}}$ & $3.24^{\mathrm{b}}$ \\
\hline Spreadable & $9.67^{\mathrm{ab}}$ & $8.90^{\mathrm{b}}$ & $10.15^{\mathrm{a}}$ & $8.54^{b}$ & $10.62^{\mathrm{a}}$ \\
\hline Melt rate & $9.82^{\mathrm{a}}$ & $8.64^{\mathrm{b}}$ & $9.52^{\mathrm{a}}$ & $8.91^{b}$ & $9.74^{\mathrm{a}}$ \\
\hline Even melt & 10.12 & 10.62 & 10.11 & $9.53^{\mathrm{b}}$ & $11.70^{\mathrm{a}}$ \\
\hline Mouthcoating & $7.36^{\mathrm{ab}}$ & $7.29^{\mathrm{b}}$ & $8.31^{\mathrm{a}}$ & 7.75 & 7.56 \\
\hline Diacetyl odor & 6.05 & 6.90 & 7.51 & 6.69 & 6.95 \\
\hline Cheesy odor & $4.09^{\mathrm{b}}$ & $3.74^{\mathrm{b}}$ & $6.73^{\mathrm{a}}$ & 4.81 & 4.23 \\
\hline Acidic odor & $2.09^{\mathrm{b}}$ & $2.62^{\mathrm{b}}$ & $6.01^{\mathrm{a}}$ & 3.98 & 3.16 \\
\hline Artificial butter odor & 3.11 & 3.16 & 4.38 & $3.88^{\mathrm{a}}$ & $3.22^{\mathrm{b}}$ \\
\hline Nutty odor & 2.98 & 2.25 & 2.18 & 2.61 & 2.33 \\
\hline Rancid odor & 2.39 & 1.53 & 2.61 & $2.81^{\mathrm{a}}$ & $1.55^{\mathrm{b}}$ \\
\hline Cardboard odor & $1.78^{\mathrm{a}}$ & $1.00^{\mathrm{b}}$ & $0.89^{\mathrm{b}}$ & 1.41 & 1.03 \\
\hline Acidic flavor & $2.75^{\mathrm{b}}$ & $3.04^{\mathrm{b}}$ & $5.69^{\mathrm{a}}$ & 4.44 & 3.22 \\
\hline Nutty flavor & $4.82^{\mathrm{a}}$ & $3.08^{\mathrm{b}}$ & $3.51^{\mathrm{ab}}$ & 3.65 & 3.95 \\
\hline Rancid flavor & 3.00 & 2.03 & 3.43 & $3.64^{\mathrm{a}}$ & $2.00^{\mathrm{b}}$ \\
\hline Artificial butter flavor & 3.45 & 3.38 & 4.24 & 3.85 & 3.53 \\
\hline Diacetyl flavor & 6.38 & 8.17 & 6.86 & $6.30^{\mathrm{b}}$ & $7.98^{\mathrm{a}}$ \\
\hline Grassy flavor & $1.35^{\mathrm{b}}$ & $1.35^{\mathrm{b}}$ & $2.05^{\mathrm{a}}$ & 1.74 & 1.42 \\
\hline Sweet flavor & 2.26 & 2.24 & 1.43 & 1.83 & 2.12 \\
\hline
\end{tabular}

${ }^{\mathrm{a}, \mathrm{b}}$ Means with different letters are significantly different $(P<0.05)$. 
Table 6. Least squares means of descriptive analysis attributes with significant type $\times$ site interaction for the 6 combinations of butter type and production site

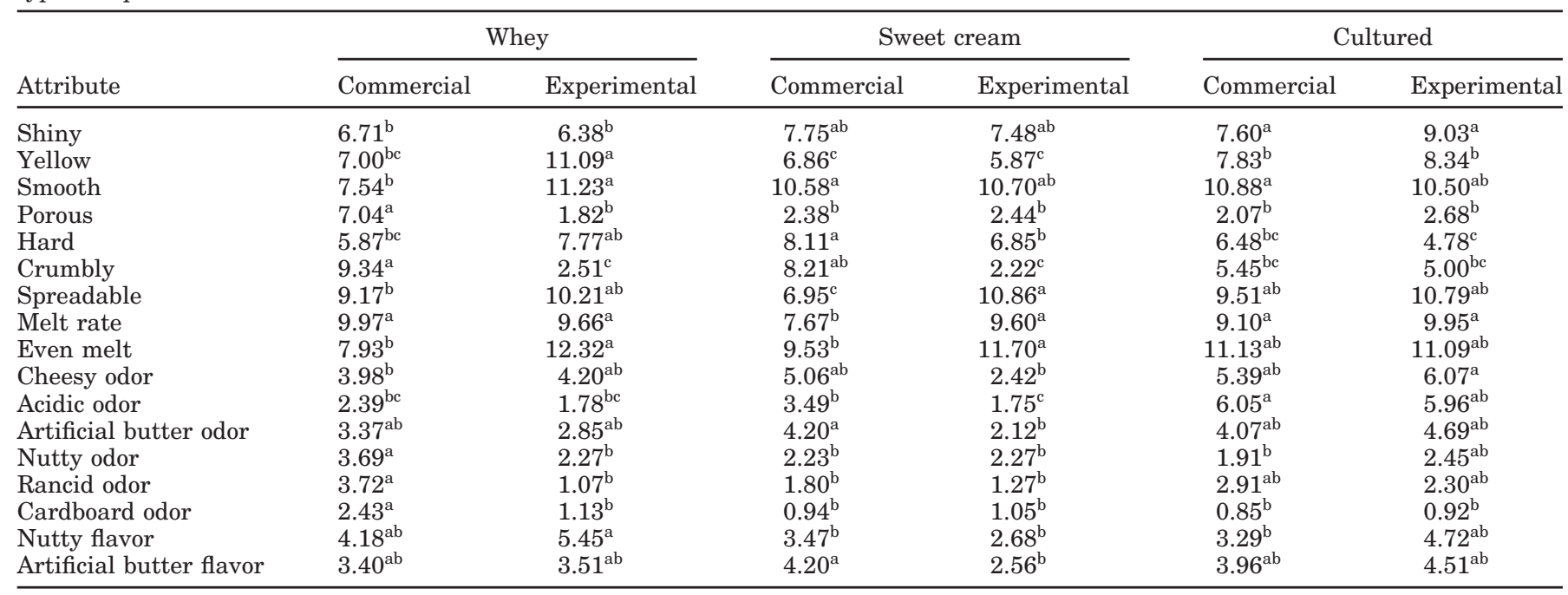

${ }^{\mathrm{a}-\mathrm{c}}$ Means with different letters are significantly different $(P<0.05)$.

relationships between butter types and sites are complex.

Table 5 shows the least squares means of the sensory attributes for the 3 different levels of butter type and the 2 production sites, and Table 6 shows the least squares means for all 6 combinations of butter type and site. For those attributes without a significant butter type $\times$ site interaction, Table 5 gives the most accurate result; however, for those sensory attributes with a significant type $\times$ site interaction, the results in Table 6 shows more complex relationships. The least squares means of the different attributes for the different butter types are summarized in Table 5 .

Cultured butters had significantly more acidic odor and flavor than WB and SB. In addition, CB had more mouthcoating than SB and was not significantly different from WB. When averaging across both production sites, CB also had more shininess and more cheesy odor and grassy flavor; however, Table 6 shows that the greater shininess of $\mathrm{CB}$ was only due to the extreme shininess of the experimental CB. The commercial CB was not significantly more shiny than SB. Similarly, the experimental CB was responsible for the increased cheesy odor. Commercial CB had more acidic odor than all other samples, although the magnitude of difference with experimental CB was small.

The commercial WB was significantly more porous than the other 5 butter combinations, and commercial WB had significantly more cardboard odor than all other butter samples. On average, WB and CB were significantly more yellow than SB. However, Table 6 shows that these differences were not significant between commercial WB and SB varieties. The experi- mental WB was significantly more yellow than all other butters studied, which was expected due to the addition of annatto extract to the milk before adding rennet and separating the whey from the curd. The experimental WB also had a significantly nuttier flavor than SB; however, the commercial WB was not significantly higher than SB in nutty flavor. Whey butter and CB had a significantly faster melting rate than the commercial SB, but not the experimental SB.

Previous studies (Guthrie, 1928) found only slight differences between sweet cream and whey butter, which was, to a certain extent, the case in this work. Significant differences between sweet cream and whey butter were obtained only for yellow, shininess, porous, melting rate, cardboard odor, and nutty flavor. As noted above, some of these differences occurred only for 1 of the 2 production sites.

Neither diacetyl odor nor diacetyl flavor was significantly higher for CB than SB and WB. These results are not in agreement with the expectation for higher scores on the above-mentioned attributes for $\mathrm{CB}$, given the production of diacetyl by cultures (Long, 1977). Schieberle et al. (1993) noted that a lower level of diacetyl odor resulted in a mild and sweet odor of butter. Although sweet odor was not used in this work, sweetness, with no significant differences between types, was negatively correlated to diacetyl odor; and WB, which had the lowest diacetyl odor intensity, had the highest sweetness intensity-although neither of these were significant differences. The differences in sweetness, although not significant, cannot be explained by differences in lactose content, because CB had the highest lactose content followed by WB (differ- 
ences not significant). Whey butter had the lowest ash content (not significant) and accordingly a lower salt content could have resulted in higher sweetness ratings. Furthermore, the lactose content could also have contributed to Maillard browning in WB, adding intensity to the yellow color of WB, which was significantly higher for WB.

Butanoic acid was found to be a major compound in fresh sweet cream butter (Schieberle et al., 1993; Peterson and Reineccius, 2003a,b); it was described as cheesy and rancid odor. Our results indicated significant difference in cheesy odor $(P<0.01)$ between types of butters, which was found in the highest intensity in CB. Boyd et al. (1999) found high proportions of polyunsaturated fatty acids, oleic acid, and linoleic acid especially from phospholipids in commercial whey powder (Boyd et al., 1999). The differences in acidic odor and flavor are expected given that cultured butters had a lower $\mathrm{pH}$ : 4.87 for CB vs. 6.12 and 6.36 for $\mathrm{SB}$ and $\mathrm{WB}$, respectively.

Whey butter was less hard and more spreadable than SB, although the differences in hardness were not significant for both attributes. Commercial SB was harder than all other samples. The findings of this work for hardness and spreadability were consistent with previous studies that showed a decrease in hardness and increase in spreadability with an increase in unsaturated fat (Bobe et al., 2003) The sensory results for hardness, although not significant, showed similar trends as the texture analysis in which SB samples were the hardest, however, diverged on CB and WB. Cultured butter was rated lower on sensory hardness measurement, whereas it had higher scores than WB in texture analysis hardness although neither of these differences was significant. It is important to note that CB was significantly less hard and more spreadable than SB.

Site of production had a significant effect on yellow $(P<0.001)$, rancid odor $(P<0.01)$, and flavor $(P<0.05)$, acidic flavor $(P<0.05)$, and diacetyl flavor $(P<0.05)$. Moreover, site of production had a significant effect on several texture/mouthfeel attributes including crumbliness $(P<0.001)$, spreadability $(P<0.001)$, porosity $(P<0.01)$, melting rate $(P<0.05)$, and even melt $(P<0.01)$. Commercial whey butter was more porous than all others. Commercial WB and commercial SB were more crumbly than their experimental counterparts, but commercial CB was not significantly more crumbly than experimental CB. Commercial SB had higher artificial butter odor than the experimental SB. Commercial WB had significantly more rancid odor than experimental WB and both SB samples. The commercial butters uniformly had more rancid flavor than the experimental butters.
On the other hand, experimental WB was more yellow than commercial WB. Experimental SB was more spreadable and had a faster melting rate than commercial SB. In addition, experimental butters were uniformly more intense on diacetyl flavor than commercial ones. The experimental butters were produced, vacuum-sealed instantly after production, and stored in the freezer, which could have resulted in significantly lower scores on some of the attributes mentioned above, such as rancid odor and flavor. Rancidity often occurs due the development of lipolysis in raw cream (Long, 1977). Nevertheless, lipolysis could continue after cream had been processed. Packaging could have been another influential factor given that experimental butters were vacuum-sealed in 3-mil polyethylene bags but commercial butters were not. One might suggest that vacuum sealing reduced the air that may cause porosity and kept texture intact therefore reducing crumbliness. Porosity in the commercial butter may be explained by nonoptimal churning at the commercial factory, where the same parameters were likely used for regular cream and whey cream in butter making.

Differences between production sites could be due to processing techniques between smaller and larger scale plants. Commercial butters had higher fat content although not significantly different from experimental butters, which could have caused the crumbliness potentially due to a higher content of large fat crystals and less liquid fat (Bodyfelt et al., 1988).

There were no major inconsistencies in the panelists' ratings, as shown by the absence of replicate effect, with the exception of sticky $(P<0.001)$, hardness $(P$ $<0.01$ ), cheesy odor, artificial butter odor, nutty odor, and grassy flavor $(P<0.05)$. Panelists had indicated difficulty assessing some of the attributes mentioned above, especially artificial butter odor and grassy flavor during training and were able to perceive it only in few samples. Furthermore, the type $\times$ replicate interaction was significant only for even melt $(P<0.05)$, whereas a significant production site $\times$ replicate interaction was obtained for shiny $(P<0.05)$ and rancid flavor $(P<0.05)$.

Principal Component Analysis. The data were analyzed after averaging across the 9 panelists and 2 batches leaving 3 replicate observations for each of the 9 butters (27 observations total). Figure 2 shows the variation accounted for by each principal component. Because of the large gap in the explained variation between components 3 and 4, only the first 3 principal components were analyzed. The first 3 principal components account for $64.95 \%$ of the variation in the sensory attribute scores. 


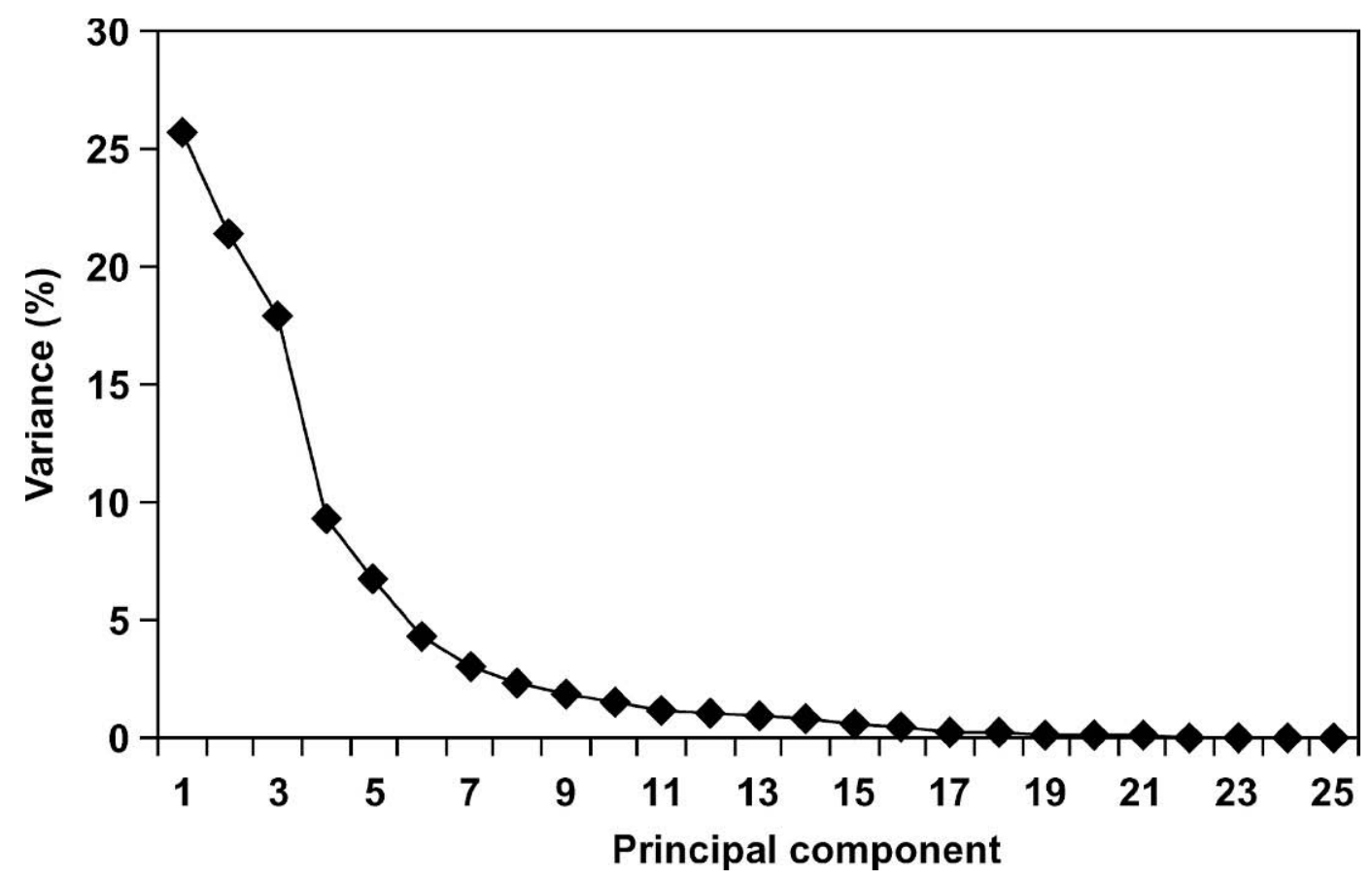

Figure 2. Scree plot of the variation accounted for by each principal component.

The results of the first 2 principal components for the butter samples are illustrated in Figure 3. The first 2 principal components explained $47.08 \%$ of the variance in the sensory attribute scores. The 3 replicate observations per butter were averaged to produce the positions of the 9 butter samples in Figure 3. There were 3 main clusters of attributes in the first 2 principal components. The first one (right upper quadrant) was characterized by attributes typically found in cultured butters such as acidic odor and flavor, diacetyl odor and grassy flavor, in addition to others, and an absence of sweet flavor. Samples 4 (commercial2 SB), 6 (commercial $1 \mathrm{CB}$ ), and 8 (commercial2 $\mathrm{CB}$ ) were included in this quadrant. On the other hand, the lower right quadrant, which included samples 1 and 9 (commercial WB and commercial $3 \mathrm{SB}$ ), had attributes typically associated with storage effects or defects such as increased rancid odor and flavor, porousness, crumbliness, and decreased smoothness, spreadability, even melting, and diacetyl flavor. The upper left quadrant, which included samples 3 (commercial1 SB) and 7 (experimental $\mathrm{CB}$ ), was the opposite; samples in that quadrant were mostly characterized by higher softness and related attributes (smooth, sticky, even melt, spreadability, etc.). These attributes were negatively correlated with the "storage effect" attributes. The lower left quadrant was characterized by higher sweetness, which was negatively correlated to "cultured but- ter" attributes, and included samples 2 (experimental WB) and 5 (experimental SB).

Acidic odor and flavor were strongly associated with cheesy odor according to Figure 3. The acidic odor and flavor in CB probably originated form high amounts of lactic acid in cultured cream, which then could have resulted in cheesy odor in CB as noted by Bodyfelt et al. (1988).

The third principal component, which is not shown in Figure 3, distinguished between shiny, yellow, smooth, hard, crumbly, diacetyl flavor, and sweet flavor compared with porous, sticky, spread, melt rate, mouthcoating, acidic odor and flavor, nutty odor, rancid odor, and cardboard odor. In Figure 3, butters 1 and 9 (commercial WB and commercial $3 \mathrm{SB}$ ) are in the same quadrant, but they differ greatly on the third principal component. The other 7 butters do not differ greatly on the third principal component, so their actual groupings based on the first 3 components are the same as those shown in Figure 3.

\section{Difference Tests and Hedonic Evaluation}

Out of the 9 triangle difference tests, a significant difference was obtained only between WB and CB (Figure 4) on pound cake. As for the acceptability tests, no significant differences were obtained for any of the 3 products. Our findings suggest that the differences 


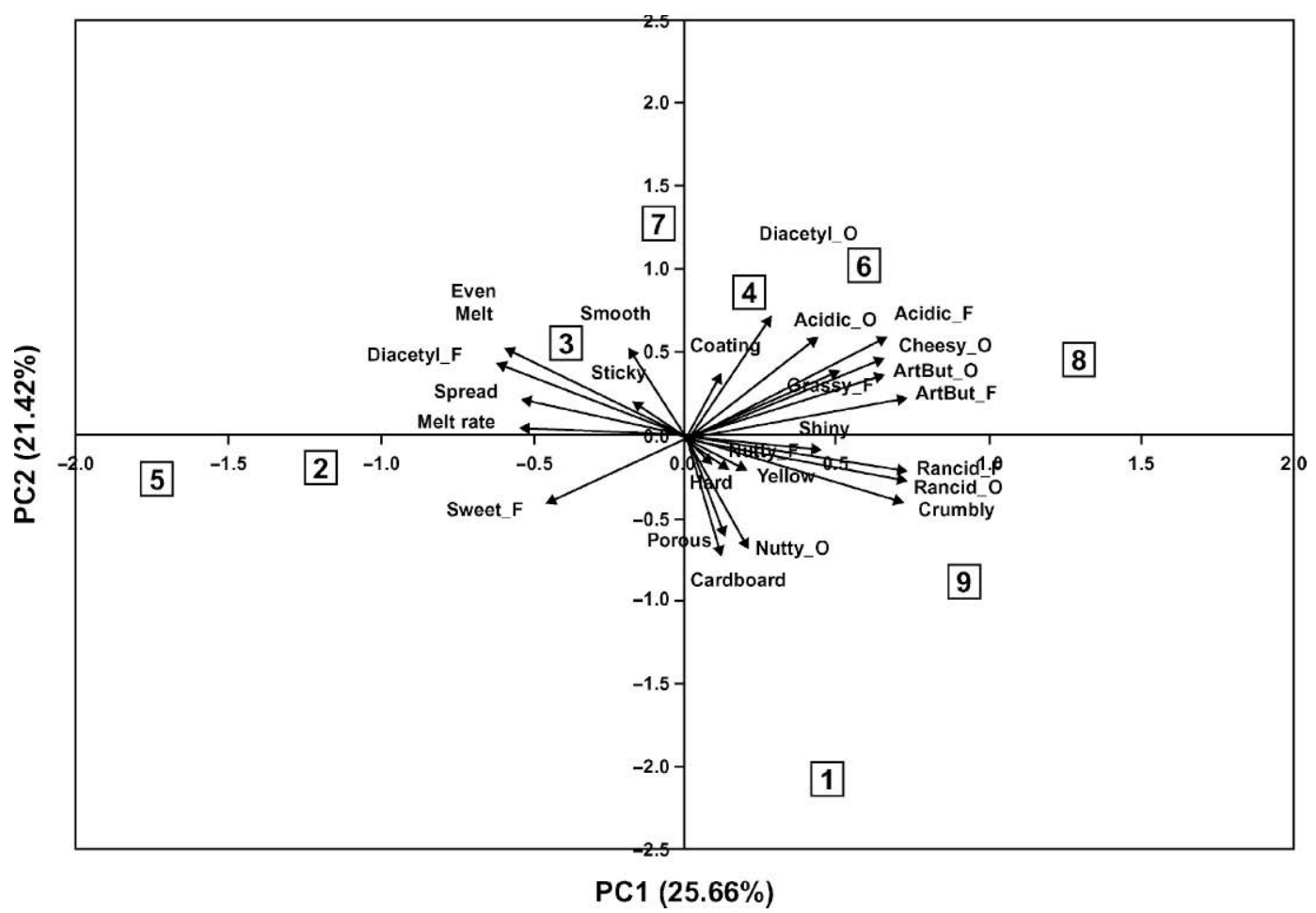

Figure 3. Principal components plot of butter samples and attributes. Sample $1=$ commercial whey butter (WB); sample $2=$ experimental WB; sample $3=$ commercial1 sweet cream butter (SB); sample $4=$ commercial2 SB; sample $5=$ experimental SB; sample $6=$ commercial1 cultured butter $(\mathrm{CB})$; sample 7 = experimental CB; sample $8=$ commercial2 $\mathrm{CB}$; sample $9=$ commercial3 SB.

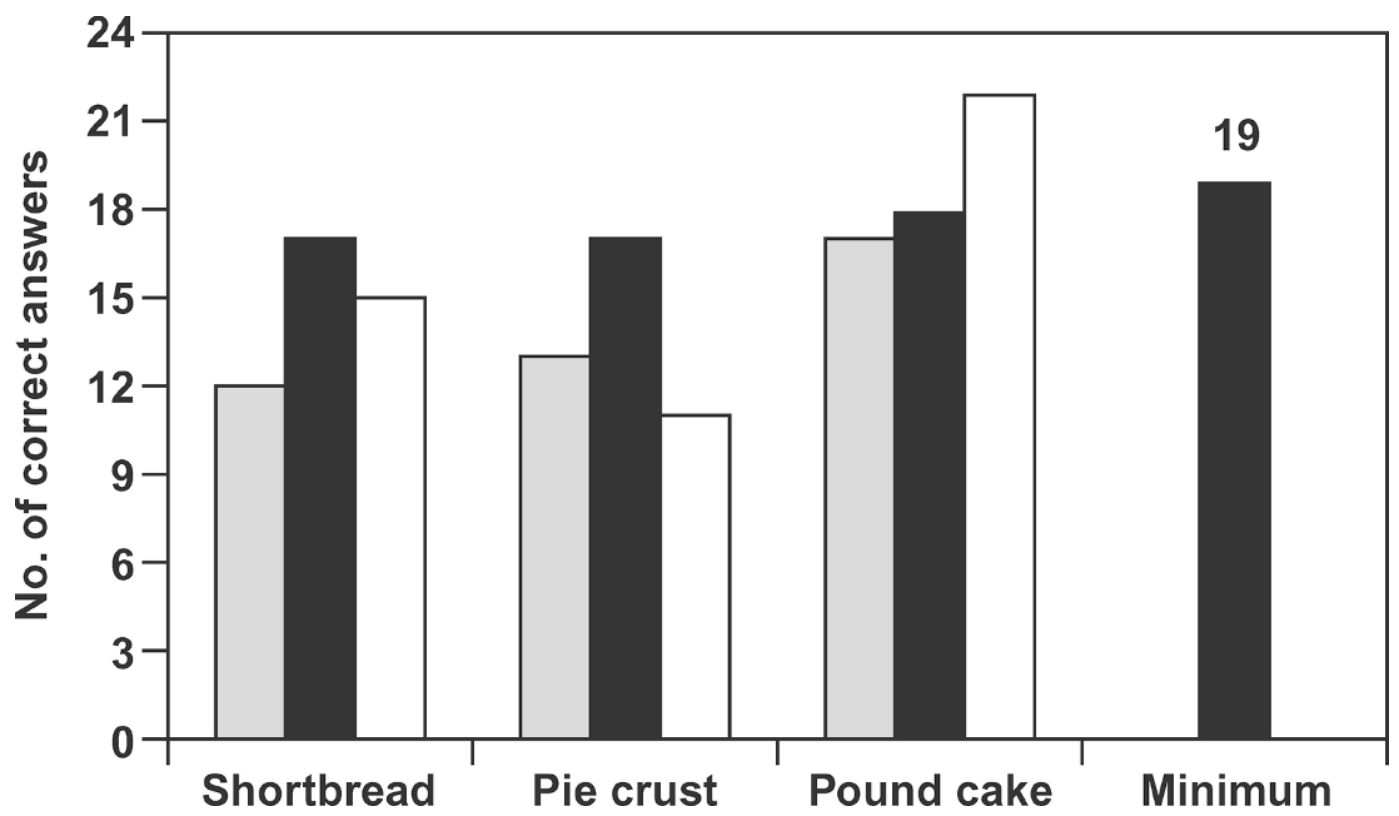

Figure 4. Number of correct answers in triangle tests for shortbread, pie crust, and pound cake (gray bars = sweet cream butter vs. whey butter; black bars = sweet cream butter vs. cultured butter; white bars $=$ whey butter vs. cultured butter). Minimum number of correct answers for a significant difference $(P<0.05)^{*}=19$. 
between the types of butters obtained in descriptive analysis did not translate into significant differences in the products. Given that the products assessed had butter as a main ingredient, it seems that whey butter could be a novel dairy ingredient with potential as a substitute for sweet cream butter.

\section{CONCLUSIONS}

The different types of butters differed only on the texture $(P<0.05)$ physical measurement. Whey butter had the softest texture, whereas SB was the hardest and $\mathrm{CB}$ was not significantly different from the 2 other types. Cultured butter had a significantly lower $\mathrm{pH}$ than both SB and WB, whereas SB and WB were not significantly different from each other. There were no significant differences between the different types of butters on the other physical and chemical measurements. A significant site effect was noted for total solids content $(P<0.01)$. The experimental butters had a higher percentage of solids, which could be due to differences in efficiency between the commercial and experimental production lines. In terms of sensory analyses, there were no major differences on textural characteristics between the different types of butters. One exception was a higher level of porosity for commercial whey butter as compared with the others. Commercial SB had a slower melting rate than the other butters. The CB samples were shinier than either WB. The cultured butters had stronger acidic odor and flavor than WB or SB. In addition, CB scored higher mouthcoating than SB. Commercial WB had more cardboard odor compared with the other types, although the cardboard odor in the commercial WB was not of considerable magnitude, and the experimental WB was not significantly higher in cardboard odor. No major significant differences were obtained for triangle tests, with the exception of the one for WB and $\mathrm{CB}$ in pound cake. Accordingly, similarity testing and possibly descriptive analyses should be considered for future studies on applications. No significant differences were obtained for the acceptability of the different versions of any of the 3 foods, which is not a surprising outcome to the researchers of this work, given the small differences between the samples that were not detected in the triangle tests. Accordingly, WB seems to be a promising ingredient with several potential applications, especially in products in which the more intense acidic odor and flavor of this ingredient would not be of any adverse effects. Additional work, including the assessment of whey butter in additional products and investigating the effect of processing variables on the sensory profile, in addition to shelf life studies, could further assist in the evaluation of whey butter and shed more light on its potential applications.

\section{ACKNOWLEDGMENTS}

The funding by the Agricultural Research Initiative (CA), the California Dairy Research Foundation, and the Hilmar Cheese Company is gratefully acknowledged. The authors thank Pierre Morin, Thomas Neuhaus, Marion Cook, Jessica Morton, Roth Gonzales, Wendy Lires, Lorna Lassonde, Jerry Mattas, and Candace Mar for their technical assistance, and all the panelists for their dedication.

\section{REFERENCES}

AOAC. 1996. Official Methods of Analysis. 16th ed. Association of Official Analytical Chemists Int., Gaithersburg, MD.

Bitman, J., and D. L. Wood. 1990. Changes in milk fat phospholipids during lactation. J. Dairy Sci. 73:1208-1216.

Bodyfelt, F. W., J. Tobias, and G. M. Trout. 1988. Sensory evaluation of butter. Pages 377-417 in The Sensory Evaluation of Dairy Products. Van Nostrand Reinhold, New York, NY.

Bobe, G., E. G. Hammond, A. E. Freeman, G. L. Lindberg, and D. C. Beitz. 2003. Texture of butter from cows with different milk fatty acid compositions. J. Dairy Sci. 86:3122-3127.

Boyd, L. C., N. C. Drye, and A. P. Hansen. 1999. Isolation and characterization of whey phospholipids. J. Dairy Sci. 82:25502557.

Cebula, D. J., and K. W. Smith. 1991. Differential scanning calorimetry of confectionary fats. Pure triglycerides: Effects of cooling and heating rate variation. J. Am. Oil Chem. Soc. 68:91.

Chen, S., G. Bobe, S. Zimmerman, E. G. Hammond, C. M. Luhman, T. D. Boylston, A. E. Freeman, and D. C. Beitz. 2004. Physical and sensory properties of dairy products from cows with various milk fatty acid compositions. J. Agric. Food Chem. 52:34223428.

Dairy Facts. 2004. International Dairy Foods Association. Washington, DC.

Guthrie, E. S. 1928. Whey Butter. Pages 3-12 in Bull. Cornell Univ. Agric. Exp. Stn., Ithaca, NY.

Kaylegian, K. E., and R. C. Lindsay. 1992. Performance of selected milk fat fractions in cold-spreadable butter. J. Dairy Sci. 75:3307-3317.

Kleyn, D. H. 1992. Textural Aspects of Butter. Food Technol. 46:118-121.

Kulkarni, S., and M. K. Rama Murthy. 1986. Inter-relationship among rheological characteristics of butter measured by objective and subjective methods. Indian J. Dairy Sci. 39:65-68.

Lawless, H. T., and H. Heymann. 1999. Sensory Evaluation of Food: Principles and Practices. Aspen Publishers, Inc., Gaithersburg, MD.

Lin, M. P., C. A. Sims, C. R. Staples, and S. F. O'Keefe. 1996. Flavor quality and texture of modified fatty acid high monoene, low saturate butter. Food Res. Int. 29:367-371.

Long, H. 1977. Dairy Product Technology. Butter. Pages 435-439 in Elements of Food Technology. N. W. Desrosier, ed. AVI Publishing Company, Inc., Westport, CT.

Maubois, J. L., A. Pierre, J. Fauquant, and M. Piot. 1987. Industrial fractionation of main whey proteins. Dairy Research Laboratory, Rennes Cedex, France.

Mortensen, B. K., and H. Danmark. 1982. Factors influencing the consistency of butter. Milchwissenschaft 37:193-196.

Parodi, P. W. 1999. Symposium: A bold new look at milk fat, conjugated linoleic acid, and other anticarcinogenic agents of bovine milk fat. J. Dairy Sci. 82:1339-1349. 
Peterson, D. G., and G. A. Reineccius. 2003a. Characterization of the volatile compounds that constitute fresh sweet cream butter aroma. Flavour Frag. J. 18:215-220.

Peterson, D. G., and G. A. Reineccius. 2003b. Determination of the aroma impact compounds in heated sweet cream butter. Flavour Frag. J. 18:320-324.

Rohm, H., and F. Ulberth. 1990. Use of magnitude estimation in sensory texture analysis of butter. J. Texture Stud. 20:409-418.

SAS Institute, Inc. 1999-2000. SAS User's Guide: Statistics, Version 8.02 ed. SAS Institute, Inc., Cary, NC.

Schieberle, P., K. Gassenmeier, H. Guth, A. Sen, and W. Grosch. 1993. Character impact odour compounds of different kinds of butter. Lebensm. Wiss. Technol. 26:347-356.

Sodini, I., P. Morin, A. Olabi, and R. Jimenez-Flores. 2006. Composition and functional properties of buttermilk: A comparison be- tween sweet, sour, and whey buttermilk. J. Dairy Sci. 89:525536.

Srivastava, M. K., N. Trimurtulu, and P. P. Lohani. 1985. Utilization of by-products of dairy industries - Whey and buttermilk. J. Indian Dairy Sci. Assoc. 37:507-509.

Stegeman, G. A., R. J. Baer, D. J. Schingoethe, and D. P. Casper. 1992. Composition and flavor of milk and butter from cows fed unsaturated dietary fat and receiving bovine somatotropin. J. Dairy Sci. 75:962-970.

USDA. 1977. United States Standards for Grades of Butter. U.S. Department of Agriculture, Federal Regulation. USDA, Washington, DC.

Wright, A. J., M. G. Scanlon, R. W. Hartel, and A. G. Marangoni. 2001. Rheological properties of milkfat and butter. J. Food Sci. 66:1056-1069. 